\title{
La humanización de la medicina
}

\author{
Pedro Gutiérrez Recacha
}

Departamento de Psiquiatría. Universidad Autónoma de Madrid.

La medicina considerada como ciencia presenta una particularidad: su objeto de estudio es el propio hombre. Es cierto que otras muchas disciplinas desde las que tradicionalmente se han agrupado bajo la denominación de 'humanidades' hasta las históricamente más recientes 'ciencias humanas'han fijado en el ámbito de 'lo humano' su esfera de interés. Sin embargo, el enfoque de tales aproximaciones parece a priori alejado de la perspectiva médica. Frente a una visión del hombre que abarca múltiples dimensiones - desde la creatividad hasta las relaciones sociales- la medicina parece constreñir su campo de reflexión a un único atributo humano: la salud. Vaya por delante que el concepto de salud resulta, como poco, ambiguo y permite las más variopintas definiciones. Sin embargo, la evolución que ha experimentado la medicina en las últimas décadas, orientada por la aspiración a convertirse en una ciencia rigurosa, ha vinculado la idea de 'salud' a la de 'hecho'; prima, por tanto, la dimensión más corpórea y empírica del hombre como objeto de estudio médico. Entonces, podemos preguntarnos, ¿qué papel juegan en la ciencia o la práctica médicas otros componentes que configuran ese todo complejo que llamamos 'humanidad'? Se vislumbra un primer riesgo: el de reificar, cosificar, simplificar las realidades de lo humano. Pero el carácter humano del objeto de la labor médica no tiene por qué suponer una limitación. Antes bien, en ocasiones, contar con un objeto de estudio dotado de autoconciencia y de capacidad de comunicación puede resultar una ventaja maravillosa, que abre nuevas perspectivas metodológicas y aleja definitivamente la medicina de las ciencias más fisicalistas.

Pero cualquier reflexión sobre la 'humanización de la medicina' debe partir de un trabajo de delimitación previo que podríamos resumir en la siguien- te pregunta: ¿qué entendemos por 'humanizar’? Lo cual es tanto como preguntar: ¿qué entendemos por 'humano'? Pues, si atendemos a la significado del verbo suministrado por la Real Academia Española, humanizar no significa sino "hacer humano". Diego Gracia, en un brillante texto titulado "Por una asistencia médica más humana” (Gracia, D., 2004), parte precisamente de esta reflexión preliminar. En su opinión, no existe una única definición de 'lo humano' que pudiera ser aplicada en todo tiempo y lugar. En épocas anteriores, los modelos de 'humanismo' que se han sucedido en la sociedad occidental vendrían caracterizados por tres rasgos distintivos: su absolutismo (es decir, se impondrían con carácter de verdad absoluta sin dejar espacio a posibles excepciones), su exclusivismo (aceptar un paradigma implicaría necesariamente rechazar otros, negando cualquier atisbo de verdad en los mismos) y su racionalismo (se confiaría en la razón como criterio, postergando las dimensiones irracionales de lo humano, como los sentimientos). Empero, la denominada 'crisis de la Razón' que sacudiría a la humanidad en los siglos XIX y XX cuartearía los viejos modelos de humanidad y dejaría como corolario el hallazgo de los valores: toda apreciación, a la par que racional, es también un acto emocional, subjetivo. En expresión de Max Weber, citada por Gracia en su trabajo, la realidad humana en la actualidad se caracterizaría por un "politeísmo axiológico" al que la práctica médica no podría ser ajena. La medicina debería considerar, pues, tanto hechos como valores, tema este que ha ocupado otro texto firmado también por el mismo autor (Gracia, D., 2003).

Pero, ¿la aceptación de la existencia de distintos valores que guían las apreciaciones personales supone caer en un caos relativista? Tal situación en poco podría ayudar al desempeño del médico. En 
una época en la que la medicina se ha institucionalizado parece razonable exigir algún principio rector que guíe su actividad para evitar la parálisis que todo desconcierto lleva aparejada. A mi modo de ver, tal principio - que resulta previo al reconocimiento de la pluralidad de valores y lo posibilita- existe y consiste en la aceptación del hombre como individuo, con dignidad, autonomía y libertad. Me permito así aventurar una respuesta a esa pregunta que Diego Gracia planteaba en su texto, cuya resolución era condición necesaria para continuar con este razonamiento. ¿En qué consiste 'ser humano'? Consiste, fundamentalmente, en ser individuo.

El papel que la noción de individuo ha jugado en el desarrollo político y filosófico en los últimos siglos, a mi entender, ha resultado crucial. Si bien el siglo XX se ha caracterizado por el auge de no pocas ideologías totalitarias, la sombra de éstas no puede ni debe eclipsar otros movimientos que han hecho de la defensa de la libertad individual su baluarte. El liberalismo, el anarquismo o incluso la conversión del socialismo real en socialdemocracia han puesto de manifiesto la relevancia política de la figura del individuo. Una relevancia que muy bien puede extenderse al terreno de la práctica médica, pues, como se afirma en el conocido documento Los fines de la medicina elaborado por el grupo de investigación del Hastings Center: "Los enfermos presentan sus malestares y lesiones al médico como personas; esto es lo que experimentan subjetivamente de forma más directa y lo que suele motivarles a buscar alivio. Se presentan a sí mismos como individuos, y son precisamente esos individuos los que deben constituir el punto de partida de la cura y los cuidados" (Callahan, D. et al, 2004). La individualidad del paciente ha alcanzado su máxima expresión en el conocido 'principio de autonomía'. Frente a una visión patriarcal en el que la decisión corresponde exclusivamente al médico, se ha reivindicado la libertad del paciente para elegir en aquellas cuestiones que involucren su propio sistema de valores, pues "velar por nuestra salud nos confronta con alternativas que tienen que ver con nuestro propio destino. La lucha por la salud nos obliga a cargar con la responsabilidad propia de los agentes morales que deben elegir las políticas sanitarias adecuadas a su propio bienestar" (Engelhardt, H.T., 1999, 12). La medicina, en relación a la libertad individual del paciente presenta una doble faz. Es indudable que la potencia, pues permite superar la amenaza de la pérdida de salud. Pero, por otro lado, en nombre de esa misma salud puede asimismo restringir la autonomía del sujeto. Como bien dice H. Tristram Engelhardt Jr., "la medicina nos libera de la naturaleza y nos impone la responsabilidad de escoger libremente entre las nuevas alternativas que nos ofrece, mientras que a su vez nos amenaza con un puritanismo secular en defensa de la salud y con tratar los problemas del ser humano desde un punto de vista médico y sin sentido crítico" (Engelhardt, H.T., 1999, 12-13).

La asunción de la realidad humana como realidad individual puede iluminar nuestro sendero, pero no despeja el camino de toda dificultad. Si todo sujeto tiene derecho a la autonomía, ¿cómo armonizar posibles conflictos entre autonomías individuales o, en nuestro caso, cómo garantizar la salvaguarda de la autonomía del paciente frente a la del médico? La compatibilidad entre autonomía y universalidad, ya desde la obra de Kant, constituye una cuestión polémica. De hecho, podemos considerar buena parte de las propuestas éticas del siglo XX como un intento de parchear la formulación del problema tal y como fue propuesta por el filósofo de Königsberg. Las éticas dialógicas, que tienen en Jürgen Habermas su representante más conspicuo, tal vez constituyan el caso más paradigmático de esta voluntad de continuidad, con ciertas enmiendas, del espíritu kantiano. Muchas son las críticas que podrían objetarse a estos planteamientos. Para empezar, la propia viabilidad de la propuesta. La toma de decisiones en una situación ideal de discusión en la que todo individuo involucrado en la misma pueda someter su elección a la consideración de los demás mediante el diálogo constituye una solución que difícilmente puede ser objeto de una implementación práctica - deba o no deba serlo, eso es otra cuestión que merecería mayor discusión-en la esfera de lo político.

Sin embargo, la medicina se desenvuelve en un marco específico que, al menos en este aspecto, difiere del político. El escenario más habitual en el que se desarrolla la práctica médica es la relación de dos individuos que entran en contacto: el profesional y el enfermo. Esto permite simplificar el siempre resbaladizo y a veces hueco concepto de 'consenso entre distintas partes'. Ahora el esquema se reduce a dos únicos actores: uno pone en juego una demanda de ayuda, el otro propone un determinado curso de acción que somete a la consideración del primero . Esta relación médico-paciente constituye un aspecto nuclear de la disciplina sanitaria que ha permanecido invariante desde sus mismos albores. Como bien afirma Mark A. Siegler:

"A pesar de los avances científicos del último siglo, 
ni el papel del la profesión médica en las sociedades humanas ni la relación doctor-paciente han cambiado sustancialmente. Desde los tiempos antiguos, el encuentro entre el curador y el paciente ha constituido el principal medio por el que la medicina logra sus objetivos. Esta continuidad extraordinaria tiene su raigambre en el hecho de que la medicina responde a una necesidad humana universal e invariable: ayudar a los pacientes. Es más, la mayor parte de la ayuda médica se proporciona en el encuentro directo entre paciente $y$ médico esto es, en la relación doctor-paciente". (Siegler, M.A., 2000, S20)

La herramienta que permite la comunicación entre el médico y el paciente es, por tanto, el diálogo. El diálogo es asimismo el vehículo a través del cual se pondrán en juego los valores del enfermo. De ahí que no sea suficiente que el médico tenga presente que existe una pluralidad de valores. El respeto a los valores asumidos por el enfermo implica la obligación de presentar los dictámenes del facultativo de modo que estos puedan ser interpretados desde el sistema axiológico concreto que presenta el paciente. No basta, por tanto, con el conocimiento. Es necesario también el desarrollo de habilidades específicas (de comunicación, de consejo...). Como se indica en el ya aludido documento Los fines de la medicina, conocimiento y capacidad son igualmente necesarios:

"En muchos casos, por supuesto, una técnica completamente impersonal resulta aceptable, e incluso deseable, como en traqueotomías de urgencia, reanimaciones cardiopulmonares y muchos tipos de cirugía de alta tecnología; pero lo más común es que se requieran también cuidados. Los cuidados no consisten simplemente en manifestar preocupación, conmiseración y disposición a hablar con el paciente; comprenden también la capacidad para hablar y escuchar de un modo que demuestra conocimiento de los servicios sociales y asistenciales necesarios para ayudar al paciente y a su familia a afrontar una amplia gama de problemas no médicos que pudieran acompañar, como normalmente ocurre, a su padecimiento". (Callahan, D. et al, 2004, 43-44)

Por otro lado, no conviene olvidar, como muy bien afirma Diego Gracia, que humanizar "exige unas ciertas condiciones básicas, que si no se poseen pueden generar lo contrario de lo que se van buscando, es decir, generar procesos de deshumanización" (Gracia,
D., 2004, 94). Es decir, para humanizar la práctica médica, el profesional debe actuar como humano. Si aceptamos la identificación que he propuesto en un párrafo anterior entre 'humano' e 'individuo', actuar como 'humano' vendría a significar actuar como 'individuo autónomo'. La precisión no resulta baladí, teniendo en cuenta que, a pesar de que el núcleo de la práctica médica sigue involucrando — como ya se ha comentado- a médico y paciente, el desarrollo de los sistemas sanitarios en nuestras sociedades contemporáneas ha diseñado alrededor de este eje fundamental todo un complejo panorama con nuevos elementos. El profesor Enrique Baca, director del departamento de Psiquiatría de la Universidad Autónoma de Madrid, recientemente ha propuesto un esquema explicativo del sistema sanitario caracterizado por la presencia de cuatro agentes: a los ya acostumbrados médico y paciente habría que añadirles, al menos en las sociedades occidentales, las figuras del tercer pagador (bien sea el propio Estado o una aseguradora privada) y de la industria farmacéutica. Los distintos agentes asumirían valores diferentes que fácilmente podrían entrar en conflicto. Es importante que, en estas circunstancias, el médico mantenga su independencia profesional frente a eventuales influencias externas, pues quien no toma interés en defender su propia autonomía difícilmente podrá respetar la ajena.

Por supuesto, al referirme al médico como individuo y subrayar su autonomía no pretendo afirmar que su labor deba ser arbitraria. Nada más lejos de mi intención. Si el médico es médico, lo es porque ha aprendido una técnica que puede aplicar en la práctica. Ahora bien, actuar como individuo comporta un aprendizaje específico que no puede quedar limitado a unos conocimientos aislados, ni tan siquiera a unas habilidades. Entraña una cierta interiorización de esos conocimientos y esos hábitos filtrada por la propia experiencia, esto es, una apropiación de los mismos de modo que incluso llegue a impregnar el propio carácter. Podría hablarse de la adquisición de virtudes en el sentido aristotélico. Tampoco perdamos de vista que, de acuerdo a lo que se ha venido argumentando en el presente texto, los conocimientos y habilidades que exige la práctica médica no son sólo de índole médica, sino también 'humanitaria'. En el ya aludido informe del Hastings Center se afirma:

“¿Por qué estoy enfermo? ¿Por qué he de morir? ¿Qué sentido tiene mi sufrimiento? La medicina, como tal, no tiene respuestas a estas preguntas, que no pertenecen a su esfera. $Y$, sin embargo, los 
pacientes recurren a médicos y enfermeros, en su calidad de seres humanos, en busca de algún tipo de respuesta. En estos casos, sugerimos que el profesional de la salud recurra a su propia experiencia y visión del mundo, haciendo uso no sólo de sus conocimientos médicos, sino también de los sentimientos de compasión y fraternidad entre seres humanos" (Callahan, D. et al., 2004, 43).

Mark A. Siegler (Siegler, M.A., 2000, S21) abunda en la misma línea de razonamiento, sugiriendo que son dos los valores profesionales que resultan centrales en la práctica médica: la virtud aristotélica de la phronesis, entendida como una suerte de sabiduría práctica (capacidad de determinar el curso más adecuado de acción ante cualquier situación) que incorporaría tanto la competencia clínica como la capacidad de juicio clínico; y el respeto por las personas (respect for persons), que englobaría actitudes como la compasión, la honestidad, la confianza y el reconocimiento del derecho del paciente a realizar sus propias elecciones médicas.

Creo que las dos 'virtudes' destacadas por Siegler resumen con pulcra exactitud el objetivo que pretendía alcanzar el presente texto: afirmar que la humanización de la medicina no es, ni mucho menos, incompatible con la visión técnica de la disciplina y que, en último término, exige un aprendizaje paralelo del médico que se traduce en conocimientos, habilidades y actitudes. La consecución de estas últimas, sin duda, constituye el reto más arduo, pues como bien ha señalado Diego Gracia: "Pueden enseñarse los conocimientos y pueden aprenderse las habilidades, pero los rasgos de carácter son muy difíciles de cambiar" (Gracia, D., 2004, 101). El único medio de lograrlo es la práctica diaria cara a cara con el paciente, pero contemplando a éste como individuo dotado de autonomía.

\section{BIBLIOGRAFÍA}

1. Baca, E. "Las cuatro 'lógicas' del sistema sanitario: médico, enfermo, tercer pagador e industria" (En prensa).

2. Callahan, D. et al. Los fines de la medicina. Cuadernos de la Fundació Víctor Grifols i Lucas. No 11. Barcelona. 2004.

3. Engelhardt, H.T. "Salud, medicina y libertad: una evaluación crítica”. En Libertad y Salud. Cuadernos de la Fundació Víctor Grifols i Lucas. No 1. Barcelona. 1999. Páginas 11-28.

4. Gracia, D. "Hechos y valores en la práctica y en las ciencia médicas”. Hechos y valores en psiquiatría. Triacastela. Madrid. 2003. Páginas 43-70. Publicado originalmente en: García Guillén, D. "Hechos y valores en la práctica y en la ciencia médicas”, en Bujosa i Homar, F. Et al. (eds.). Actas del IX Congreso Nacional de Historia de la Medicina. Vol. I. Zaragoza. Servicio de Publicaciones de la Universidad. Páginas 37-63.

5. Gracia, D. "Por una asistencia médica más humana". En Como arqueros al blanco. Estudios de bioética. Triacastela. Madrid. 2004. Páginas 93-102.

6. Siegler, M.A."Professional values in modern clinical practice". The Hastings Center Report; Jul/Aug 2000; 30, 4; Health Module pg S19-S22.

Por supuesto, la suposición asumida a lo largo de este texto de que el paciente se halla dotado de autonomía puede resultar, en algunos casos cuestionable. Estoy pensando en el ejemplo por antonomasia: los enfermos mentales. Pero en este caso se considera que la limitación a la autonomía del enfermo no vendría impuesta (al menos, teóricamente) por la intervención del facultativo, sino por el propio trastorno. De hecho, el profesional médico actúa en esta situación (o debería actuar) como 'albacea' o 'representante' de la propia autonomía del sujeto, es decir, de aquella autonomía perdida de la que el sujeto disfrutaría de no estar lastrado por un trastorno mental. 